\title{
Mature Cystic Teratoma of the Ovary; Clinicopathological Evaluation of 143 Cases in our Series, 5 Years Experience
}

\author{
Ferah KAZANCI'1 , Betul OGUT², Dilek YAPAR ${ }^{3}$, Ozlem ERDEM², M. Anil ONAN' \\ Ankara, Turkey
}

\section{ABSTRACT}

OBJECTIVE: Mature cystic teratoma, also known as a dermoid cyst, is the most common germ cell tumor of the ovary. In this retrospective study, it is aimed to evaluate clinicopathological findings of the patients who were operated on due to the preliminary diagnosis of dermoid cyst.

STUDY DESIGN: Between May 2013 and May 2018, the findings of a total of 143 patients who were operated on with a preliminary diagnosis of dermoid cyst in our institution were analyzed retrospectively. In addition to demographic characteristics such as age, parity number and tumor size, lateralization, preoperative tumor markers, surgical procedure, presence of other pathological findings, and the rate of malignant transformation were analyzed.

RESULTS: The median age of patients was 35.4 years and the ratio of nulliparous, primiparous, and multiparous patients was $46.9 \%, 25.2 \%$, and $28 \%$, respectively. The median tumor diameter was 6.7 $\mathrm{cm}, 50.3 \%$ of which were right-sided, $46.9 \%$ were left-sided and the remaining $2.8 \%$ were bilateral. Intraoperative torsion was found in $15(10.5 \%)$ cases. The treatment consisted of $60.1 \%$ cystectomy by laparoscopy, 3.5\% unilateral salpingo-oophorectomy by laparoscopy, $9.8 \%$ unilateral salpingooophorectomy by laparotomy, while the rate of $16.1 \%$ cases underwent hysterectomy with bilateral salpingo-oophorectomy by laparotomy, $10.5 \%$ of the cases, cysts were excised during cesarean section. As the final pathology report revealed, of 143 patients, immature teratoma was observed in five cases $(3.5 \%)$, in one of them $(0.7 \%)$ mixed germ cell tumor and in three of them $(2.1 \%)$ borderline mucinous cancer, squamous cell carcinoma, and carcinoid tumor on mature cystic teratoma base were observed.

CONCLUSION: Torsion is the most common complication with mature cystic teratoma. The size of the tumor is an important prognostic factor in terms of the malignant transformation of teratoma. Fertility sparing surgery with a minimally invasive surgical approach is available for fertility patients diagnosed with Mature cystic teratoma.

Keywords: Dermoid cyst, Malign transformation, Mature cystic teratoma, Size, Torsion

Gynecol Obstet Reprod Med 2021;27(3):283-288

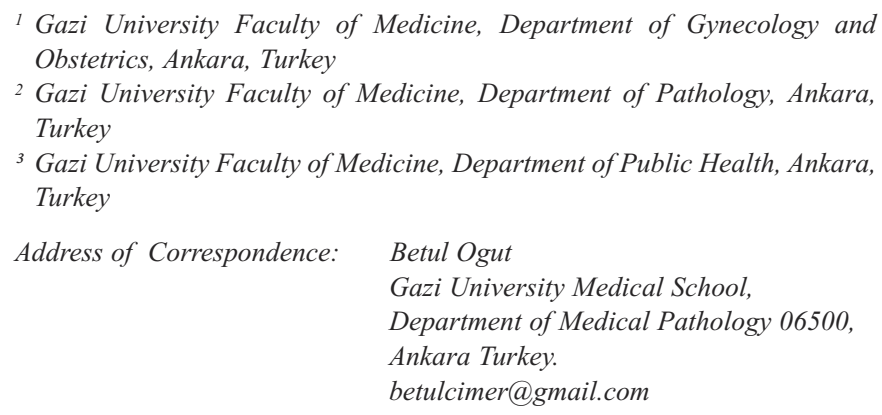

Submitted for Publication: 15.02.2021 Revised for Publication: 19.02.2021 Accepted for Publication: 14.08.2021 Online Published: 31.08.2021

ORCID IDs of the authors: $\quad$ FK: 0000-0002-3910-0821 BO: 0000-0002-1385-7324, DY: 0000-0001-7656-1152 OE: 0000-0002-8396-458X, MAO: 0000-0001-7643-1585

\begin{tabular}{|c|c|}
\hline \multirow{3}{*}{ 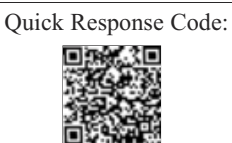 } & Access this article online \\
\hline & $\begin{array}{l}\text { Website: www.gorm.com.tr } \\
\text { e- mail: info@gorm.com.tr }\end{array}$ \\
\hline & DOI:10.21613/GORM.2021.1189 \\
\hline
\end{tabular}

How to cite this article: Kazanci F. Ogut B. Yapar D. Erdem O. Onan MA. Mature Cystic Teratoma of the Ovary; Clinicopathological Evaluation of 143 Cases in our Series, 5 Years Experience. Gynecol Obstet Reprod Med. 2021;27(3):283-288

\section{Introduction}

Mature cystic teratoma (MCT), also recognized as dermoid cyst, is the most common germ cell tumor of the ovary. It constitutes $10-20 \%$ of all ovarian tumors and is the most common benign ovarian tumor (1). These tumors originating from three germ layers are frequently observed between the ages of 20-40 (2). Teratomas developed from three germ layers such as ectoderm, endoderm, and mesoderm are classified according to mature and immature cells; immature, mature, and monodermal teratoma are subtypes (3). Most of them are asymptomatic until symptoms such as pain and abdominal mass are seen due to torsion, rupture, infection, or malignant transformation. It can be detected incidentally during routine physical examination, radiological evaluation, and abdominal surgery for different reasons (4). Transvaginal ultrasonography is the most important diagnostic method for early detection of teratomas and the image is pathognomonic due to the fatty component (5). The detection rate of mature cystic teratomas by tumor markers is low (6). The bilaterality ratio of 
MCTs is $10 \%$ and torsion is the most common complication in $15 \%$ of cases. The rate of malignant transformation varies between $1-2 \%$ and occurs in older ages.

The most common malignant transformation in MCT is squamous cell carcinoma and it is seen at a rate of $70-80 \%$ in mature teratomas $(7,8)$. Although the exact cause of malignant transformation is unknown, it is assumed that the presence of long-term mature cystic teratoma and squamous metaplasia in the columnar epithelium result from the malignant change. Rarely, adenocarcinoma, small cell carcinoma, carcinoid tumor, various sarcomas, and malignant melanoma can be observed together $(8,9)$. Malignant transformation of MCT may show local invasion and peritoneal implantation, and the clinical symptoms of affected organs can be observed $(10,11)$. MCTs should be surgically removed due to the growth of sizes and complications such as rupture, torsion, infection, and malignant transformation. Standard treatment is ovarian cystectomy with laparotomy? or laparoscopic methods or oophorectomy for perimenopausal and postmenopausal women. Cystectomy should be performed by laparoscopic method especially in young patients (12).

\section{Material and Method}

Between May 2013 and May 2018, 143 patients were operated on with the preliminary diagnosis of dermoid cyst in our institution. The findings of those 143 patients were analyzed retrospectively in this cross-sectional study,. Besides the demographic characteristics such as age, the number of pregnancy and parity and tumor size, lateralization, preoperative tumor markers, surgical procedure and methods, the presence of other pathological findings (such as endometrioma, fibroid, serous cyst), malignant transformation rates was analyzed, too. The data of evolution are obtained from patients' pathology reports and electronic files. SPSS software version 22.0 is used for statistical analysis of the research data.

We used descriptive statistics as categorical and continuous variables. Categorical variables were represented by number and percentage and continuous variables were presented as mean \pm standard deviation for normally distributed data and median (minimum-maximum value) for non-normally distributed data. As a result of the analysis, it was found that the continuous variables in this study were not coherent with the normal distribution. The Mann-Whitney $\mathrm{U}$ test was used to compare these inconsistent analyses among double grouped results. ROC analysis was performed to determine whether the cyst diameter has a valuable cut-off in predicting malignancy in cases with teratoma. Values of $p<0.05$ were considered statistically significant.

Ethics committee approval was received by the ethics committee of our faculty (727 date 08.10 .2018 ). All procedures were performed according to the declaration of Helsinki.

\section{Results}

The median age of patients was 35.4 years (ranging from 15 up to 81 years old). The rate of the patients with nulliparous, primiparous, and multiparous was respectively $46.9 \%$, $25.2 \%$, and $28 \%$. The average diameter of the tumors is 6.7 $\mathrm{cm}$, ranging in size from $2 \mathrm{~cm}$ to $20 \mathrm{~cm}$. While $50.3 \%$ of the tumors were right-sided, $46.9 \%$ of them were left-sided. The remaining $2.8 \%$ were also bilateral localization. Intraoperative torsion was found in $15(10.5 \%)$ cases (Table I). Torsion was the most common complication among all other complications. Considering the benign pathological rate of the findings, $5.6 \%$ endometrioma, $4.2 \%$ myoma, $0.7 \%$ serous cyst, $0.7 \%$ mucinous cyst, $1.4 \%$ corpus luteum cyst, and $0.7 \%$ Morgagni cyst were detected simultaneously with teratomas. $60.1 \%$ of the patients were treated by cystectomy, $3.5 \%$ unilateral salpingo-oophorectomy by laparoscopy, $9.8 \%$ unilateral salpingooophorectomy by laparotomy. While $16.1 \%$ of the cases underwent hysterectomy with bilateral salpingo-oophorectomy, in one of the cases diagnosed as immature teratoma with pathology, pelvic and paraaortic lymphadenectomy and omentectomy were performed. In addition, appendectomy was performed for one which was reported as a borderline mucinous tumor. In fifteen $(10.5 \%)$ cases, cysts were excised during cesarean section. In $2(1.4 \%)$ cases, cysts were detected in antenatal follow-up and $13(9.1 \%)$ cases were incidentally observed during cesarean section (Table II). Malignant pathological results were reported in 10 of 143 patients operated on with a preliminary diagnosis of dermoid cyst. Five cases $(3.5 \%)$ were reported with immature teratoma by the final pathology, one of them $(0.7 \%)$ was with mixed germ cell tumor and one of them $(0.7 \%)$ was with rectal carcinoma besides teratoma. One of them was reported with borderline mucinous tumor, one was with squamous cell carcinoma, and one was with carcinoid tumor observed on mature cystic teratoma base. The last three cases constitute $(2.1 \%)$ of the total cases. The average age of patients with and without malignancy was respectively, $38 \pm 24.5 \quad(\mathrm{~min}=17-\mathrm{max}=81), 33 \pm 12 \quad(\mathrm{~min}=15$ $\max =74$ ) and there were no statistically significant differences (Mann-Whitney test; $p=0.313$ ).

Table I: Evaluation of demographic and clinical data of mature cystic teratoma cases

\begin{tabular}{ll}
\hline Demographic features & $\mathrm{n}($ mean; \%) \\
\hline Age(min-max) & $35.4 \pm 13.4(15-81)$ \\
Cyst diameter (min-max) & $6.7 \pm 3.0(2-20 \mathrm{~cm})$ \\
Nulliparous & $67(46.9)$ \\
Primiparous & $36(25.1)$ \\
Multiparous & $40(28)$ \\
Localization & \\
Right-sided & $72(50.3)$ \\
Left-sided & $67(46.9)$ \\
Bilateral & $4(2.8)$ \\
Torsion & $15(10.5)$ \\
Total $(\mathrm{n})$ & 143 cases \\
\hline
\end{tabular}


Table II: Distribution of applied surgical methods in mature cystic teratoma cases

\begin{tabular}{lc}
\hline Surgical method & $\mathrm{n}(\%)$ \\
\hline Laparoscopy cyst excision & $86(60.1)$ \\
Laparoscopy salpingo-oophorectomy & $5(3.5)$ \\
Laparotomy salpingo-oophorectomy & $14(9.8)$ \\
TAH+BSO & $23(16.1)$ \\
C /S + Cyst excision & $15(10.5)$ \\
Total & 143 \\
\hline
\end{tabular}

As a result of ROC analysis, cyst diameter had a diagnostic value to predict malignancy in patients with teratoma (AUC $=0.775 ; \% 95 \mathrm{CI}=0.620-0.929 ; p=0.004)$, and the cut-off value was determined as $6.5 \mathrm{~cm}$ (sensitivity $90 \%$, specificity $61 \%$, Figure1).

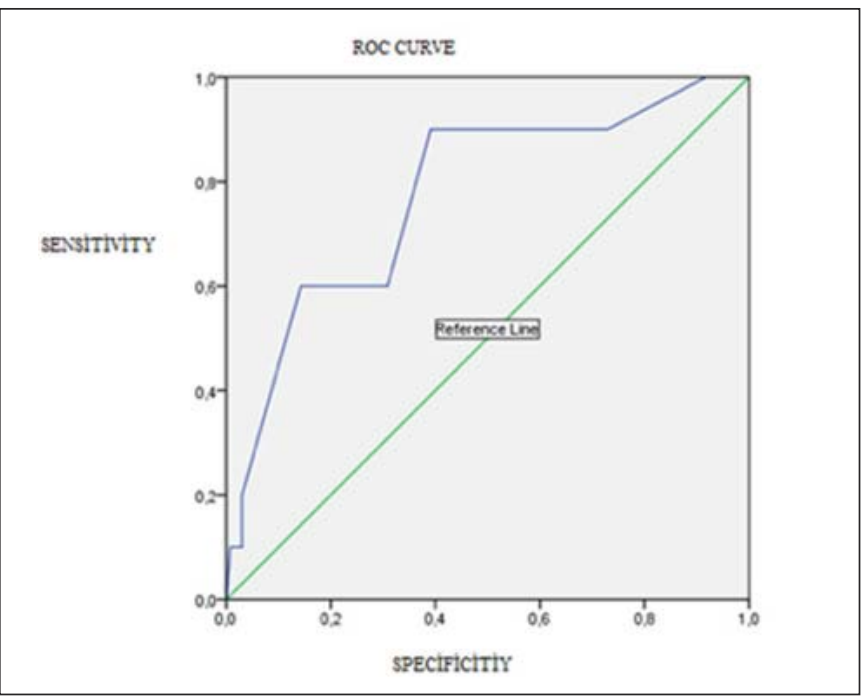

Figure 1: Receiver operating characteristic analysis to evaluate sequence matching, analysis curve of cyst diameter of 143 individuals included in the study.

The effect of risky conditions on malignancy in teratomas was investigated by univariate binary logistic regression analysis. It was determined after the result of the analysis that cyst diameter $\geq 6.5 \mathrm{~cm}$, the value of AFP level $\geq 9 \mathrm{ng} / \mathrm{mL}$, and the value of CA-125 level $\geq 35 \mathrm{U} / \mathrm{mL}$ were found to be effective on the malignancy diagnosis (Table III).

\section{Discussion}

Mature cystic teratoma is accepted as the most frequently seen benign ovary tumor that constitutes $10-20 \%$ of the total (13). Teratomas could exist in any age but it is frequently seen between the ages 20-40 (14). In this study, the average interval of age is $35.4 \pm 13.4$, which is coherent with previous studies. It is important to diagnose MCT in the early phase so that conservative ovary operation could be used easily and it has less effect on puberty and fertility because MCTs are often seen in the reproductive period (15). It is presumed that MCTs are seen in this age group because it comes out of only the primordial germ cell that completes meiosis 1 and represses meiosis 2 (16). More than $90 \%$ of mature cystic teratomas are unilateral and located on the right side. Bilaterality is between $8 \%$ and $15 \%$ (17). In this study, $50.3 \%$ of the tumors were on the right ovary and $46.9 \%$ were on the left. $2.8 \%$ were bilateral and this rate was lower than in the literature. Patients with mature cystic teratoma could have pain, menstrual disorder, and some other urinary and gastrointestinal complaints due to the pressure caused by the diameter of the mature cystic teratoma, and they are mostly asymptomatic and seen during the gynecological examination or incidentally during the surgery (18-20). In this study, 25 of the patients $(17.4 \%)$ had a tumor over $10 \mathrm{~cm}$ diameter and pain along with complaints related to the pressure while 15 (10.5) of the cases were urgently operated on because of torsion, and in $13(9.1 \%)$ patients, MCT was incidentally seen during the ceasarean section.

The most frequently seen complications of mature cystic teratoma are torsion, rupture, and malignant transformation. The torsion frequency changes between $3.5 \%$ and $9.2 \%$ interval in literature, and the torsion frequency was $10.5 \%$ in this study (21). Ayhan et al. determined $4.9 \%$ torsion in their study which includes 501 patients (1). The size of the tumor in torsioned cases is usually bigger than the average but it is thought

Table III: Evaluation of the effect of cyst diameter and tumor markers on malignancy transformation

\begin{tabular}{lllll}
\hline & Maliginite Positive $n^{*}$ & Maliginite Positive $\%$ & $\begin{array}{c}\text { OR } \\
(95 \% \mathrm{Cl})^{* *}\end{array}$ \\
\hline $\begin{array}{l}\text { Cyst diameter }(\mathrm{n}=143) \\
<6.5 \mathrm{~cm} \text { (reference) }\end{array}$ & $1 / 82$ & 1.2 & 1 & $14.02(1.73-113.93)$ \\
$\geq 6.5 \mathrm{~cm}$ & $52 / 61$ & 85.2 & & 0.004 \\
AFP (n=92) & $5 / 88$ & & 1 & $16.60(1.10-143.62)$ \\
$<9$ (reference) & $2 / 4$ & 5.7 & & \\
$\geq 9$ & & 50 & 1 & 0.011 \\
Ca-125(n=104) & $4 / 91$ & & $6.53(1.27-33.43)$ \\
$<35$ (reference) & $10 / 13$ & 4.4 & &
\end{tabular}

${ }^{*}$ Number of patients with malignancy/number of all patients. ${ }^{* *} \mathrm{OR}$ : Odds Ratio 
that the increase in dimension may not be the reason but could be the result (22). In this study, the average cyst diameter in torsioned cases is $8 \pm 4$ while it is $6 \pm 2.7$ in the ones without torsion, the fact that the diameter of the cyst is increasing while the torsion rate is increasing (Mann-Whitney test; $p=0.014$ ) was found statistically significant.

Rupture is a very rare complication that causes granulomatous peritonitis via leaking the liquefying sebaceous cyst ingredient into the peritoneal gap (23). Rupture is not found in this study.

Malignant transformation is usually seen in postmenopausal women, it is rare and its incidence changes between $0.2 \%$ and $4 \%$. Peterson determined $1.8 \%$ malignant transformation among 8000 patients with MCT, Hurwitz et al. determined 1-2\%, and Kim et al. 0.6\% (24-26). The Taiwan Oncology Group that includes Chiang et al. determined $0.2 \%$ that comes from the results of ten different studies which constitute metanalysis (27). Sherpa et al. determined 3\%, Rathore $3.5 \%$, and Bedir et al. determined 4\% (28-30).

Squamous cell carcinoma could come out of any component of mature cystic teratoma, which is seen in almost $80 \%$ of malignant cases (31). Less often than squamous cell carcinoma; thyroid carcinomas, adenocarcinomas, and carcinoid tumors could be seen (26). In this study, in only one case $(0.7 \%)$, squamous cell carcinoma in teratoma was seen, in one case $(0.7 \%)$ borderline mucinous tumor in teratoma, and in one case $(0.7 \%)$ on teratoma base, carcinoid tumor was seen (Figure 2). The malignant transformation rate of these cases was $2.1 \%$, which supports the relevant literature. About MCT, the ages of the patient and the dimension of the tumor are important for the development of malignant transformation (17). In the studies done by Chiang, Sherpa, and Rathore, et al, the average age of the patients was $52,47.5$, and 40 , respectively. The dimension of the tumors was determined as $10.5,10.8$, and $10 \mathrm{~cm}(27-29)$. The average age was 55 and the average dimension of the tumor was 10 and over in the study in which 277 patients with squamous cell carcinomas, the malignant transformation was researched in 126 articles published between 1978 and 2007 (31,32). In this study, the average age was $38 \pm 24.5$ among the patients with malignant transformation while it was $33 \pm 12.0$ in the one without malignant transformation, which was not statically significant (MannWhitney test; $p=0.313$ ). In this study, 3 patients aged 53, 37, and 81 were diagnosed with malignant transformation on teratoma base. Immature teratoma was determined in 5 patients who were diagnosed with MCT operated by the researchers, in another patient, a mixed germ cell tumor was seen and all malign cases were evaluated together while statistics were done. The average dimension of the tumors was $10 \pm 4.3 \mathrm{~cm}$ in the cases with malignant transformation while it was $6 \pm 2.8 \mathrm{~cm}$ in the ones without malignant transformation. The difference was found significant (Mann-Whitney test; $p=0.003$ ). ROC analyses showed that the dimension of the cyst of the patients who have teratoma diagnosis is valuable in predicting malignancy and the limit value is determined as $6.5 \mathrm{~cm}$ (sensitivity $90 \%$ specificity 61\%) (AUC: $0.775 ; \% 95$ GA=0.620-0.929; $p=0.004$ ). No certain correlation was seen between malignant transformation and serum tumor indicators but in some cases, high levels of CA-125 or CA19-9 were accompanied $(31,33)$. In this study, serum AFP level $\geq 9 \mathrm{ng} / \mathrm{mL}$ and CA-125 level $\geq 35 \mathrm{U} / \mathrm{ml}$ were found to be effective on malignancy.
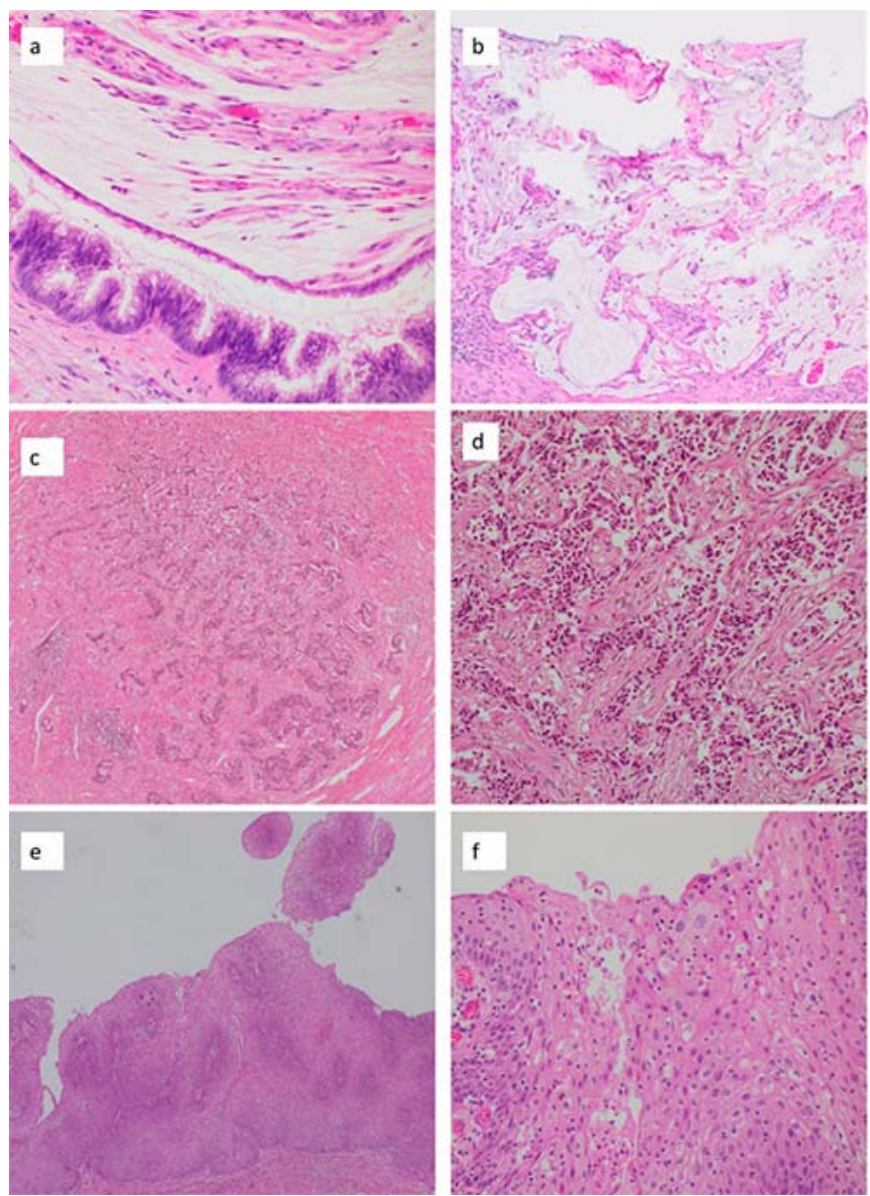

Figure 2a: Mucinous borderline tumor lining with proliferating pseudostratified epithelium (H\&E stain, x100. b: Myxoid infiltration associated with pseudomyxoma peritonei (H\&E stain x200). c,d: Carcinoid tumor infiltration in cyst wall (H\&E stain $x 40$ and $x 400$, respectively) e,f: Squamous cell carcinoma in situ in cyst wall (H\&E stain $\times 100$ and $\times 200$, respectively).

Ultrasonography is mostly used to diagnose MCT (34). In this study, apart from $9.1 \%$ incidentally diagnosed cases, all cases of MCT were diagnosed via ultrasonography in the preoperative era.

Oophorectomy was the most used principal procedure for MCT in the previous period (35). Because MCTs are usually seen in women in the reproductive period, the operative approach should be as conservative as possible. Oophorectomy or salpingo-oophorectomy is suitable for young patients who have suspicious malignancy or for the women in postmenopausal period (1). In $101(70.6 \%)$ of our cases, cyst ex- 
cision $(60.1 \%$ of them laparoscopy, $10.5 \%$ of them laparotomy) was applied, for $13.3 \%$ of them salpingo-oophorectomy and for $16.1 \%$ of them, total abdominal hysterectomy and bilateral salpingo-oophorectomy were performed.

Considering the cases in which total abdominal hysterectomy and bilateral salpingo-oophorectomy were used, malignancy, myoma, cyst, descensus, and other gynecologic problems were indications for surgery. Age, fertility desire, and additional pathologies must be considered in deciding how to treat $\mathrm{MCT}$.

Mature cystic teratoma is the most seen benign ovary tumor in the reproductive period and preoperative ultrasonography is the most important indicator. They are usually unilateral and the risk of malignant transformation is low and the incidental diagnosis during the operation is high. Additionally, torsion is the most seen complication of these tumors. Older age and the dimension of the cyst are the most risk factors in malignant transformation. The most suitable operative approach is laparoscopic cyst excision if it is not malignant.

Declarations: Ethics approval and consent to participate All participants signed informed written consent before being enrolled in the study.

The informed consent was taken from patients before surgery that the study was conducted in accordance with the Declaration of Helsinki.

Availability of data and materials: The data supporting this study is available through the corresponding author upon reasonable request.

Competing interests: The authors declare that they have no competing interests.

Funding: None

Authors' contributions: FK:, OE:, and AO: Raised the presented idea. FK:, BO:, and DY: Designed the study. DY: Conducted the analyses. FK:, OE: and BO: Developed the first draft of the manuscript. All authors contributed to the writing of the paper, and have read and approved the final manuscript.

\section{References}

1. Ayhan A, Bukulmez O, Genc C, Karamursel BS, Ayhan A. Mature cystic teratomas of the ovary: case series from one institution over 34 years. Eur J Obstet Gynecol Reprod Biol. 2000;88(2):153-7. Doi:10.1016/s0301-2115 (99)00141-4.

2. Frederick J, DaCosta V, Wynter S, Tenant I, McKenzie C, McDonald Y. Endometriosis co-existing with bilateral dermoid cysts of the ovaries treated by laparoscopy. West Indian Med J. 2003;52(2):179-81. PMID: 14506771.

3. Malkasian GD, Symmonds RE, Dockerty MB. Malignant ovarina teratomas. Report of 31 cases. Obstet Gynecol. 1965;25:810-4. PMID: 14287472.

4. Mecke H, Savvas V. Laparoscopic surgery of dermoid cysts--intraoperative spillage and complications. Eur J Obstet Gynecol Reprod Biol. 2001;96(1):80-4. Doi:10. 1016/s0301-2115(00)00390-0.

5. Bazot M, Cortez A, Sananes S, Boudghene F, Uzan S, Bigot JM. Imaging of dermoid cysts with foci of immature tissue. J Comput Assist Tomogr. 1999;23(5):703-6. Doi: 10.1097/00004728-199909000-00012.

6. Stany MP, Hamilton CA. Benign disorders of the ovary. Obstet Gynecol Clin North Am. 2008;35(2):271-84, ix. Doi:10.1016/j.ogc.2008.03.004.

7. Zakkouri FA, Ouaouch S, Boutayeb S, Rimani M, Gamra L, Mrabti H, et al. Squamous cell carcinoma in situ arising in mature cystic teratoma of the ovary: a case report. J Ovarian Res. 2011;4:5. Doi:10.1186/1757-2215-4-5.

8. Avcı S, Selcukbiricik F, Bilici A, Ozkan G, Ozağari AA, Borlu F. Squamous cell carcinoma arising in a mature cystic teratoma. Case Rep Obstet Gynecol. 2012;2012: 314535. Doi:10.1155/2012/314535.

9. Song W, Conner M. Squamous cell carcinoma arising within a mature cystic teratoma with invasion into the adjacent small intestine: a case report. Int J Gynecol Pathol. 2012;31(3):272-5. Doi:10.1097/PGP.0b013e31823b6f53.

10. Kikkawa F, Ishikawa H, Tamakoshi K, Nawa A, Suganuma N, Tomoda Y. Squamous cell carcinoma arising from mature cystic teratoma of the ovary: a clinicopathologic analysis. Obstet Gynecol. 1997;89(6):1017-22. Doi:10.1016/s0029-7844(97)00117-8.

11. Gooneratne AT, James AO, Gupta J, Abdulaal Y. Squamous cell carcinoma arising in a mature cystic teratoma invading the sigmoid colon: a rare presentation. BMJ Case Rep. 2015;2015:bcr2014208472. Doi:101136/ bcr-2014-208472.

12. Morgante G, Ditto A, la Marca A, Trotta V, De Leo V. Surgical treatment of ovarian dermoid cysts. Eur J Obstet Gynecol Reprod Biol. 1998;81(1):47-50. Doi:10.1016/ s0301-2115(98)00139-0.

13. Matz MH. Benign cystic teratomas of the ovary. A review. Obstetr Gynecol Surv. 1961;16:591-605. Doi:10.1094/ 00006254-196110000-00001.

14. Sah SP, Uprety D, Rani S. Germ cell tumors of the ovary: a clinicopathologic study of 121 cases from Nepal. J Obstet Gynaecology Res. 2004;30(4):303-8. Doi:10.1111 /j.1447-0756.2004.00198.x.

15. Azizkhan RG, Caty MG. Teratomas in childhood. Curr Opin Pediatr. 1996;8(3):287-92. Doi:10.1097/00008480199606000-00018.

16. Linder D, McCaw BK, Hecht F. Parthenogenic origin of benign ovarian teratomas. The N Engl J Med. 1975;292 (2):63-6. Doi:10.1056/NEJM197501092920202.

17. Ozgur T, Atik E, Silfeler DB, Toprak S. Mature cystic teratomas in our series with review of the literature and retrospective analysis. Arch Gynecology Obstet. 2012;285 (4):1099-101. Doi:10.1007/s00404-011-2171-8. 
18. Ong HC, Chan WF. A clinico-pathological review of benign cystic teratoma of the ovary. Singapore Med J. 1977; 18(2):100-4. PMID: 929220.

19. Badmos KB, Ibrahim OK, Aboyeji AP, Omotayo JA. Squamous cell carcinoma arising in a mature cystic ovarian teratoma with bladder invasion: a case report. Afr Health Sci. 2011;11(2):285-7. PMID: 21857863.

20. Eskicioglu F, Gökmen T. Evaluation of ovarian mature cystic teratomas in our clinic: 110 cases. Tepecik Egit Hast Derg. 2016;26(1):23-6. Doi:10.5222/terh.2016.023. 21.

21. Hursitoglu BS, Demirtas GS, Demirtas O, Akman L, Yilmaz H. A clinico-pathological evaluation of 194 patients with ovarian teratoma: 7-year experience in a single center. Ginekol Pol. 2013;84(2):108-11. Doi:10.17772/ $\mathrm{gp} / 1549$.

22. Saba L, Guerriero S, Sulcis R, Virgilio B, Melis G, Mallarini G. Mature and immature ovarian teratomas: CT, US and MR imaging characteristics. Eur J Radiol. 2009;72(3):454-63. Doi:10.1016/j.ejrad.2008.07.044.

23. Fossey SJ, Simson JN. Sclerosing encapsulating peritonitis secondary to dermoid cyst rupture: a case report. Ann R Coll Surg Engl. 2011;93(5):e39-40. Doi:10.1308/ 147870811 X582495.

24. Peterson WF. Malignant degeneration of benign cystic teratomas of the overy; a collective review of the literature. Obstet Gynecol Surv. 1957;12(6):793-830. Doi:10. 1097/00006254-195712000-0001.

25. Hurwitz JL, Fenton A, McCluggage WG, McKenna S. Squamous cell carcinoma arising in a dermoid cyst of the ovary: a case series. BJOG. 2007;114(10):1283-7. Doi: 10.1111/j.1470-0528.2007.01478.x.

26. Kim SM, Choi HS, Byun JS, Kim YH, Kim KS, Rim SY, et al. Mucinous adenocarcinoma and strumal carcinoid tumor arising in one mature cystic teratoma of the ovary with synchronous cervical cancer. J Obstet Gynaecol Res. 2003; 29(1):28-32. Doi:10.1046/j.1341-8076.2003.00073.x.

27. Chiang AJ, Chen MY, Weng CS, Lin H, Lu CH, Wang $\mathrm{PH}$, et al. Malignant transformation of ovarian mature cystic teratoma into squamous cell carcinoma: a Taiwanese
Gynecologic Oncology Group (TGOG) study. J Gynecol Oncol. 2017;28(5):e69. Doi:103802/jgo.2017.28.e69.

28. Sherpa P BR, Kansakar TK. Malignant transformation arising in mature cystic teratoma. J Pathol Nepal. 2016;6 (12):981-4. Doi:10.3126/jpn.v6i12.16267.

29. Rathore R, Sharma S, Arora D. Clinicopathological evaluation of 223 cases of mature cystic teratoma, ovary: 25 year experience in a single tertiary care centre in India. $\mathrm{J}$ Clin Diagn Res. 2017;11(4): EC11-EC14. Doi:10.7860/ JCDR/2017/23909.9612.

30. Bedir R, Güçer H, Şehitoğlu İ, Bağcı P, Yurdakul C, Balık $\mathrm{G}$, et al. Mature cystic teratoma of the ovary: a clinicopathologic study of our series and retrospective analysis. J Clin Obstet Gynecol. 2013;23(4):225-30.

31. Hackethal A, Brueggmann D, Bohlmann MK, Franke FE, Tinneberg HR, Munstedt K. Squamous-cell carcinoma in mature cystic teratoma of the ovary: systematic review and analysis of published data. Lancet Oncol. 2008; 9(12):1173-80. Doi:10.1016/S1470-2045(08)70306-1.

32. Katabuchi H, Mikami M, Nagase S, Okamoto A, Ito K, Morishige K, et al. Japan Society of Gynecologic Oncology guidelines 2015 for the treatment of ovarian cancer including primary peritoneal cancer and fallopian tube cancer. Int J Clin Oncol. 2016;21(3):435-46. Doi: 10. 1007/s10147-016-0985-x.

33. Ustunyurt E, Gungor T, Iskender C, Ustunyurt BO, Bilge U, Mollamahmutoglu L. Tumor markers in mature cystic teratomas of the ovary. Arch Gynecol Obstet. 2009;279 (2):145-7. Doi:10.1007/s00404-008-0688-2.

34. Patel MD, Feldstein VA, Lipson SD, Chen DC, Filly RA. Cystic teratomas of the ovary: diagnostic value of sonography. AJR Am J Roentgenol. 1998;171(4):1061-5. Doi: 10.2214/ajr.171.4.9762997.

35. Morillo Conejo M, Martín Cañadas F, Muñoz Carmona V, González-Sicilia Muñoz E, González Sicilia Cotter E, Carrasco Rico S. Teratoma maduro de ovario. Estudio clínico-patológico de 112 casos y revisión de la literatura [Ovarian mature teratoma. Clinico-pathological study of 112 cases and review of the literature]. Ginecol Obstet Mex. 2003;71:447-54. PMID: 14686056. 